Cita bibliográfica: Ramón Puebla, A. M., Salinas Chávez, E., Millán Escriche, M., Labrada Vega, O. y Rosales Espinosa, Y. (2020). Evaluación de los recursos paisajísticos e históricos para el desarrollo del turismo de naturaleza en las zonas de uso público del Parque Nacional Pico Bayamesa. Cuba. Investigaciones Turísticas (19), pp. 213-239. https:// doi.org/10.14198/INTURI2020.19.10

\title{
Evaluación de los recursos paisajísticos e históricos para el desarrollo del turismo de naturaleza en las zonas de uso público del Parque Nacional Pico Bayamesa. Cuba
}

\section{Evaluation of landscape and historical resources for the development of nature tourism in the areas of public use of the Pico Bayamesa National Park. Cuba}

Adonis Maikel Ramón Puebla (iD, Órgano de Montaña Gramma, Cuba adonis.ramon@nauta.cu

Eduardo Salinas Chávez iD, Universidade Federal de Mato Grosso do Sul, Brasil esalinasc@yahoo.com

Mercedes Millán Escriche (iD, Universidad de Murcia, España memillan@um.es

Osiris Labrada Vega (iD, Empresa para la Protección de la Flora y la Fauna, Parque Nacional Pico Bayamesa, Cuba

co8olv@frcuba.co.cu

Yordanis Rosales Espinosa (iD, Empresa Agroforestal Gramma, Cuba yordanis.15@nauta.cu

\section{RESUMEN}

Se realiza la evaluación de la propuesta actual de uso público del Parque Nacional Pico Bayamesa, del Plan de Manejo 2017-2021, abarcando los atractivos localizados en cada zona propuesta para uso público dentro del Parque y las opciones propuestas para el desarrollo del turismo de naturaleza, así como la viabilidad de este a partir de diversos indicadores de evaluación, propuestos en la metodología analizada; las estrategias para el desarrollo del turismo en áreas protegidas y los programas de uso público. A partir de la aplicación de estas metodologías, se realiza el inventario y clasificación de los atractivos presentes en las zonas de uso público, atendiendo a sus características y grado de atracción, evaluando además las propuestas actuales de senderos. En función de esa clasificación realizada a los atractivos y empleando otros indicadores como son: accesibilidad, estado de conservación, calidad, cantidad y limitantes 
para su uso. Se realiza una nueva propuesta de zonas de uso público y de posibles senderos para esta área protegida.

Palabras clave: Áreas Naturales Protegidas; Uso Público; Evaluación de atractivos; Cuba

\section{ABSTRACT}

This paper evaluates the current proposal concerning the public use of the Pico Bayamesa National Park. This usage is included the 2017-2021 Management Plan. It covers activities for each of the park's proposed areas, along with suggested options for additional development. The paper looks at the feasibility of nature tourism using a variety of indicators. The paper also includes a summary of strategies for tourism development in protected and public use areas. It looks at current trail proposals taking into account the characteristics of these trails and their degree of attractiveness. The evaluation uses a variety of methodologies including: inventory listings and the degree of the trails' attractiveness. Other indicators examined are trail accessibility, their conservation status, type of usage and the quality and quantity of this usage. Finally, the paper also includes a new proposal of public use areas and possible trails for this protected area.

Keywords: Natural Protected Areas; Public Use; Attractiveness evaluation

\section{INTRODUCCIÓN}

El turismo, como actividad de acelerado crecimiento en las últimas décadas del siglo pasado y las primeras de este siglo, busca nuevos espacios y se diversifica en un mundo cada vez más globalizado, pero esta expansión, de forma masiva, afecta en muchos casos a las áreas protegidas que tienen altos valores naturales y culturales, especialmente en aquellos territorios con rica diversidad biológica, como son las islas y las montañas tropicales. Según diferentes autores y organismos (UNEP y UNWT, 2012), en la última década del siglo XX y la primera del siglo XXI, el turismo en las áreas naturales del mundo, han crecido a un ritmo de hasta el $20 \%$ anual, lo que significa entre 4 y 5 veces más que el turismo convencional, lo que se refleja en la afluencia de más de 8.000 millones de visitantes por año a las Áreas Naturales Protegidas (Balmford et al., 2015) y que está asociado, entre otros factores, según Vacas (2010) con:

- El aumento del número de áreas protegidas a nivel mundial.

- Un creciente interés de la sociedad por los temas relacionados con la conservación de la naturaleza y el medio ambiente.

- La mayor divulgación de estas áreas en los medios de comunicación y, especialmente, en Internet.

- La moda ecológica que nos vende el reencuentro con la naturaleza y las actividades al aire libre.

- El incremento del nivel de vida de la población, su poder adquisitivo y su nivel de formación.

- Sumándose a este incremento de visitantes, incluso, los turistas convencionales que viajan a destinos naturales (Bushell y Eagles, 2007). 
Por otra parte, las más de 100.000 áreas protegidas de diversa categoría, que se encuentran distribuidas por todo el planeta, están concebidas como áreas donde el uso del suelo prioriza la conservación y se hallan principalmente bajo administración pública, cuya finalidad es mantener, al menos parcialmente, determinadas características de estos espacios. Dichas áreas son creadas, entre otros objetivos, con el propósito de asegurar la conservación de los paisajes, ecosistemas y especies emblemáticas; hacer accesible al público territorios de alto valor estético; mantener la biodiversidad y conservar territorios que encierran importantes eventos de la historia de la Tierra. Todo ello intentando proteger alrededor del $12 \%$ de su superficie. No obstante, estas áreas, que fueron concebidas con objetivos primordiales de conservación, como ya mencionamos, son actualmente utilizadas para funciones diversas, tales como las ecológicas, económicas y sociales, destacándose entre ellas el turismo (Leung, Spenceley, Hvenegaard y Buckley, 2019).

Entendiendo sus ventajas y desventajas, el turismo en las Áreas Naturales Protegidas es una realidad en el mundo actual y resulta conocido que ha generado controversia desde sus inicios. Estos, según algunos autores, se remontan a la creación de los primeros Parques Nacionales en los EE UU, a finales del siglo XIX, tras la pérdida masiva de diversas especies de fauna en todo el mundo. A partir de ahí, fue posible la consolidación de diversas sociedades para la protección de la flora y la fauna que impulsaron la declaración de numerosas áreas protegidas y su posterior conversión, desde las primeras décadas de siglo XX, en áreas icónicas para la protección de algunas especies.

Por otro lado, la mejora del nivel de vida, de una parte importante de la población de los países desarrollados, después de la Segunda Guerra Mundial, convirtió a la naturaleza y, por ello, a las áreas protegidas en objeto de deseo de las sociedades capitalistas desarrolladas, convirtiendo a las mismas, y a la naturaleza en su conjunto, en productos turísticos listos para ser comercializados y consumidos, mediante la apropiación del patrimonio por el turismo como activo rentable (Prats, 2003, Fontoura, et al., 2016).

Conviene, en este punto, señalar que, desde la perspectiva conceptual, el turismo, que se realiza en las áreas naturales protegidas, puede ser definido como: aquel que se lleva a cabo en áreas declaradas de conservación en sus diversas categorías y, de acuerdo con estas, cuyo objetivo fundamental ha de ser la conservación de los valores naturales y culturales que las han hecho merecedores de protección. Por esa razón, la diversificación de actividades permitidas y su grado de intensidad deben estar en función de la categoría de protección del espacio y de la zonificación de uso establecida en los planes de uso y gestión (Vacas, 2010, Zalles, 2018, Eagles, et al., 2002, Garzón y Ramírez, 2018).

En el caso concreto de Cuba, podemos señalar que las 211 áreas protegidas, identificadas dentro del Sistema Nacional de Áreas Protegidas, representan el 20,20\% del territorio nacional, incluyendo la plataforma insular marina hasta la profundidad de $200 \mathrm{~m}$. Entre estas, 14 áreas se encuentran comprendidas en la categoría de Parque Nacional y ocupan más de 9.000 kilómetros cuadrados; de los cuales, solamente siete brindan uso público e incluyen actividades turísticas (Centro Nacional de Áreas Protegidas, 2013). Mención especial dentro de este apartado merece el Parque Nacional Viñales y su entorno, que constituye un área emblemática a nivel mundial de karts de montañas tropicales y que, en los últimos años, está 
recibiendo cerca de medio millón de visitantes anuales que realizan diversas actividades turísticas relacionadas con la naturaleza y la cultura (Moretti, Salinas y Ribeiro, 2016). Asimismo, el Parque Nacional Ciénaga de Zapata, considerado el mayor humedal del Caribe insular, donde más de 100.000 visitantes realizan anualmente actividades de observación de aves, espeleoturismo y visitas a lugares históricos, asociados con los destacados atractivos naturales e histórico-culturales de la región (Salinas y Cámara, 2016).

Por otro lado, existe un grupo de áreas protegidas de diversas categorías, con elevado potencial para el uso público, en las que actualmente no se desarrolla ninguna actividad turística. Muchas veces, esto ocurre por falta de una adecuada valoración de sus atractivos y la presentación de ofertas que cubran las expectativas del segmento turístico que visita estos espacios. Así ocurre en el caso del Parque Nacional Pico Bayamesa que, contando con importantes atractivos paisajísticos e históricos, dentro de sus zonas de uso público, y una propuesta preliminar de senderos para uso turístico, ya incluidas en el Plan de Manejo 2013-2017, hasta la fecha no ha podido concretar ninguna actividad turística.

En este sentido, destaca la idoneidad y oportunidad de esta investigación, puesto que se propone, como objetivo principal, inventariar y evaluar los recursos paisajísticos e históricos del Parque Nacional Pico Bayamesa. Para ello será necesario valorar la propuesta de uso público existente y establecer las adecuaciones oportunas que, finalmente, posibiliten aprovechar los recursos paisajísticos de esta área protegida.

Asimismo, para conseguir el objetivo principal propuesto se establecen los siguientes objetivos específicos:

- OE1 Evaluar la propuesta actual de uso público del Parque Nacional Pico Bayamesa, presentada en el Plan de Manejo 2017-2021,

- OE2 Inventariar los atractivos reconocidos por el Plan de Manejo 2017-2021 en cada zona propuesta hoy como uso público dentro del Parque y las actividades recomendadas para el turismo de naturaleza; así como la viabilidad de las mismas,

- OE3 Clasificar los atractivos atendiendo a sus características y su grado de atracción.

Como se apunta en el apartado correspondiente, estos propósitos exigen la utilización de aquellos métodos de investigación que mejor contribuyan a su resolución.

\section{EL USO PÚBLICO EN LAS ÁREAS NATURALES PROTEGIDAS}

Desde el punto de vista conceptual, el uso público, es un término relativamente reciente, no solo en la teoría sino en la práctica de la gestión en las áreas naturales protegidas. Según EUROPARC-España (2005) y Hernández de la Obra y Gómez-Limón (2005), se entiende como uso público: al conjunto de programas, servicios, actividades y equipamientos, que deben ser provistos por parte de las instancias administrativas responsables de la ordenación y gestión del área protegida, con el objetivo de facilitar el disfrute, conocimiento, interpretación y/o valoración, de la misma, de forma ordenada y segura, garantizando la conservación, la comprensión y el aprecio de tales valores mediante la información, la educación y la interpretación del patrimonio natural y cultural. 
Para otros autores, el concepto de uso público es empleado para indicar la utilización de las áreas naturales protegidas por el público, por medio de las visitas y el turismo, independientemente de cuál sea su motivación (contemplación, recreación, deporte, etc.), o del segmento de turismo en cuestión: ecoturismo, turismo ecológico o de aventura (Rodrigues, 2009). El uso público debe ser considerado, por lo tanto, un concepto con mayor amplitud de miras, puesto que incluye a los turistas y también a aquellos que viven en el entorno y practican el ocio en las áreas protegidas, además de los investigadores y personas relacionadas con las actividades de conservación y educación ambiental que se relacionan con las mismas.

Como señala EUROPARC (2005), las diversas definiciones de uso público, utilizadas por los diferentes organismos internacionales, presentan algunos criterios comunes que le son esenciales, como: el acercamiento a los valores de los recursos naturales y culturales del área protegida, la contribución a la conservación, la necesidad de que los usos y actividades estén ordenados y el carácter recreativo, cultural y educativo de su práctica (MVOTMA, 2014; Morea, 2016; Rodrigues, Pinheiro do Nascimento, 2012, Antón, 2008, Garzón y Arias, 2008, Vilas, 2004).

Para Gómez-Limón y García (2014),

"la diversidad de motivaciones, intereses y necesidades de los individuos que visitan los espacios naturales es enorme. Estas están en función de la edad, nivel de formación, lugar de procedencia, tamaño del grupo que realiza la visita y frecuencia de la misma, entre otros. Unos pretenden solo recibir información sobre el espacio visitado, otros hacer deporte, aquellos profundizar en algún tema específico, y la mayoría, simplemente unos momentos de contacto, esparcimiento y relajación en la naturaleza». (p. 21)

Pero no hay duda que, en la medida en que las actividades recreativas, los deportes al aire libre y el conocimiento de dicha naturaleza, son ofrecidas y vendidas por las agencias de viaje, los turoperadores y otros agentes, a un público cada vez más amplio, mediante la creación de necesidades inexistentes, en muchas ocasiones, y el discurso ambientalista que lo acompaña, para satisfacer el sueño de muchas personas de tener contacto con la naturaleza, ya sea verdadera o recreada en espacios protegidos o cercanos a ellos (Rodrigues, 2009, Artigues-Bonet, Blázquez-Salom, 2016), puede incurrirse en rebasar los límites de la capacidad de acogida de estos ámbitos que, por su valor ecológico y/o paisajístico, merecen protección (Medina-Castro, 2019).

Junto a esa demanda de uso recreativo/turístico, existe un interés por participar en los beneficios procedentes de los visitantes y turistas (EUROPARC, 2002), por lo que autores como Blázquez (2005), señalan que, el uso público (turístico, recreativo, científico o educativo) del patrimonio debe centrarse en los valores que lo hacen merecedor de ser protegido. Con esta premisa debe evitarse su banalización o transformación, para satisfacer apetencias o preferencias de la demanda, que lo alejen de sus valores reales (Cebrián y Sánchez, 2015) y la cuestión fundamental a considerar es que el aprovechamiento turístico, recreativo o interpretativo de la naturaleza en un área protegida, es decir, su uso público, tiene como propósito contribuir al bienestar de la población local y de la sociedad en general y debe comprometerse con su 
conservación, para lo cual debe estar ligado a los valores que la hacen merecedora de ser protegida. Por lo tanto, debe anteponerse la conservación al uso y este precepto debe regir también la modulación del uso, con el fin de evitar que peligre la existencia de estos valores y, al mismo tiempo, alcanzar el máximo rendimiento sin que la experiencia contemplativa y recreativa pierda en calidad, por lo que debe planificarse mediante un enfoque sistémico e integral (MVOTMA, 2014, Morea, 2016, Muñoz-Santos y Benayas, 2012).

Como señala Morea (2016), existen experiencias muy interesantes en este sentido, como son: la "Guía metodológica para la planificación del uso público en Argentina», y la propuesta de «Evaluación del Uso Público en la Red de Parques Nacionales de España» y considera que esta última es un caso particular, ya que propone una metodología, de evaluación de la calidad del uso público, que permite identificar las reglas para su planificación, mediante la evaluación de diversos aspectos que influyen en el mismo, como son: los accesos, la zonificación, los programas de interpretación, educación ambiental y gestión del visitante, así como diversos aspectos económicos, entre otros. Estas guías, y otros trabajos realizados, proponen incluir en la zonificación de las áreas naturales protegidas, las zonas de uso público como espacios que cumplen la función de soporte a la actividad del turismo de naturaleza, y que han sido definidas por APN (2001), como las áreas que contienen atractivos naturales y/o culturales que se consideran aptos y compatibles con la visita y el disfrute público, sin comprometer su conservación o permanencia, pudiendo diferenciarse, a su vez, dos zonas en función de la intensidad y carácter de las actividades permitidas, el tipo de uso del suelo compatible y las oportunidades y demandas que generan los atractivos presentes en el área. Estas zonas son:

- De Uso Público Extensivo: aquellas áreas que, por sus características, permiten el acceso del público con restricciones, de forma tal que las actividades y usos aceptados tengan un impacto mínimo sobre los sistemas o componentes naturales o culturales. Las actividades y usos permitidos son los contemplados en la zona de conservación, área núcleo o intangible según son nombrados en los diversos países, a los que se agrega el uso científico, educativo y turístico recreativo de tipo extensivo, es decir, ni masivo, ni concentrado. Además, en materia de infraestructura, solamente se admite la construcción de facilidades mínimas y de bajo impacto (senderos, miradores, refugios, observatorios de fauna, campamentos de tipo agreste, refugios de montaña, etc.).

- De Uso Público Intensivo: son las áreas que, atendiendo a sus características, admiten una mayor concentración de visitantes y actividades de más alto impacto, compatibles con los objetivos de la conservación del área. Las actividades y usos admitidos son los contemplados en las zonas anteriores a los que se agrega el uso público masivo, aunque siempre sujeto a las regulaciones existentes en este sentido. En este caso, se admite la construcción e instalación de servicios de mayor envergadura para la atención de los visitantes (campamentos organizados con servicios, centro de visitantes, estacionamientos, servicios gastronómicos, alojamientos cuando corresponda, etc.). Esta zona debe ser limitada en extensión con respecto a la superficie total del área protegida.

Otros autores, como Del Reguero (2004), proponen al menos tres divisiones dentro de la zona de uso público de un área protegida y, de forma sintetizada, pueden concretarse en: 
- Zona de visita muy controlada o vedada. Son aquellas zonas, de alto valor ecológico, que pueden estar declaradas como reserva integral, que apenas admiten visitas salvo las científicas y algunas educativas pero muy restringidas en número. Nunca estarán equipadas con infraestructuras de alojamiento o similares.

- Zona de visita controlada o mesurada, que permite la visita turística, pero siempre con limitaciones, en grupos pequeños y, casi siempre, guiados por personal especializado. Es la zona de los grupos educativos numerosos y la de los turistas en grupos reducidos. En esta zona los ecosistemas están ya modificados, la mayoría de las veces, o representan espacios rurales en fase de abandono. Se admite entonces la ubicación de equipamientos de uso público, educativos y de alojamiento de poca carga turística o estacionales, no estables, ni fijos. Si hay pueblos en ellos, encontraremos algunas casas relacionadas con el agroturismo.

- Zona de visita intensiva. No contempla restricción al paso de personas ni al transporte público o privado (automóvil). Aquí se ubica la mayoría de la infraestructura de acogida, preferentemente en los pueblos previamente existentes. Se utilizan espacios ya degradados como canteras o minas, previamente rehabilitados para ciertos usos masivos.

En Cuba, se considera, según Gerhartz, et al (2007, p. 48), a la zona de uso público, "como aquella que dentro del área protegida se dedica fundamentalmente a actividades de recreación y educativas». Señalan estos autores que, generalmente, son de fácil acceso y poseen muestras representativas de las características, especies, ecosistemas y paisajes del área protegida, pero sin que constituyan sus valores fundamentales, por lo que pueden tener cierto grado de alteración y requerirán de una infraestructura específica, así como acciones de manejo y un eficiente sistema de monitoreo del impacto de los visitantes, tanto sobre el medio natural como sobre la infraestructura. Estas zonas de uso público, según los autores, antes mencionados, se dividen en subzonas que se determinan en función de la carga máxima de visitantes y el tipo de actividad a realizar y que son:

- De uso extensivo: áreas donde debe limitarse el número de visitantes diarios y en las que la infraestructura será la imprescindible con vistas a garantizar la seguridad y provocar un impacto mínimo en el funcionamiento natural de los ecosistemas.

- De uso intensivo: donde se concentra la infraestructura más masiva, como los servicios básicos (posta médica, áreas de venta, servicios sanitarios), los accesos viales, senderos de corta duración y elevada capacidad de carga, centro de visitantes, campamentos y áreas de acampada entre otros. Esta área debe limitarse al máximo para promover el disfrute, la educación ambiental y la protección del visitante, en un entorno natural que es el objetivo fundamental de la visita a las áreas protegidas.

Independientemente de la clasificación de la zona de uso público que se seleccione, los objetivos de esta zona, según Salinas y Ramón (2017), siempre van a estar en función de:

- Evaluar, inventariar y promover la utilización sostenible del potencial natural para el desarrollo de diversas actividades relacionadas con la conservación de la naturaleza.

- Transformar los programas de uso público, turismo y recreación para las áreas protegidas en factores dinamizadores del desarrollo local. 
- Involucrar a la población de la zona en las acciones del programa de educación ambiental destinadas al manejo sostenible de los recursos naturales, al incremento de la cultura ambiental y al mejoramiento de la calidad de vida de los pobladores.

- Promover investigaciones y acciones de conservación, manejo y aprovechamiento de los recursos naturales, a partir de los resultados y experiencias obtenidas en el monitoreo.

\section{METODOLOGÍA}

En consonancia con los objetivos planteados, se ha considerado apropiado realizar una investigación de tipo cualitativo descriptivo, apoyada en la observación directa del caso de estudio. Dicha metodología se acepta ampliamente para analizar temas actuales, o fenómenos contemporáneos sobre los que el investigador no tiene ningún control, porque permite estudiar algo específico dentro de un fenómeno complejo y comprender las dinámicas actuales en contextos particulares. Además, el estudio de casos resulta muy útil para diagnosticar y hacer propuestas, lo que es el objetivo de esta investigación. No obstante, hay que considerar que, en el caso concreto que aquí se presenta, ya se parte de una situación conocida, como es la propuesta de uso público existente, pero que, mediante esta aportación, se busca establecer las adecuaciones oportunas para un mejor aprovechamiento de los recursos paisajísticos existentes en el área analizada. Por eso mismo, puede valorarse idónea la postura de Hiernaux (2008), quien considera que este tipo de estudios no puede seguirse alimentando solamente de datos estadísticos, por oficiales que sean. Dice el autor que el "campo» es la materia prima, el escenario donde se presentan las prácticas socio-espaciales de los turistas y de esos "otros» con los que interactúan en el acto turístico y, cabe añadir que, para los geógrafos, la observación "es un hecho cotidiano que forma parte de la percepción en los acontecimientos diarios» (Díaz, 2011 p. 18), pero es, a la vez, "un método fundamental en el proceso de investigación, además de ser la herramienta de donde se obtienen la mayor cantidad de datos empíricos» (Centeno y De la Garza, 2014 p. 205).

Asimismo, el apoyo a la metodología utilizada se encuentra en Báez y Acuña (2003), quienes consideran que los atractivos turísticos de un área pueden clasificarse en tres categorías: atractivos focales, complementarios y de apoyo.

- Atractivos focales: son los elementos distintivos del patrimonio natural y/o cultural que se encuentren en un área. Se trata de aquellos rasgos intrínsecos de singularidad que mejor caracterizan al sitio o región y el motivo fundamental por el cual los turistas desean visitarlo y puede considerarse el «mito turístico».

- Atractivos complementarios: son aquellos elementos del patrimonio natural y/o cultural que se encuentran en un área determinada, pero que no poseen el grado de importancia o singularidad en cuanto a atracción turística de los anteriores. No obstante, constituyen motivos de interés adicional y valor agregado para el turista, contribuyendo a enriquecer la experiencia, al inducir al visitante a que permanezca mayor tiempo en el área, evitando concentraciones excesivas de visitantes en un lugar único y propiciando el desplazamiento de los mismos por el área. 
- Servicios de apoyo: componen aquellos elementos artificiales (instalaciones y servicios) que proporcionan al visitante la satisfacción de sus necesidades básicas durante la visita al sitio. Aquí se incluyen: alojamiento, restaurantes, centros de interpretación, senderos y miradores, servicios para paseos a caballo o en lancha, etc. Dan sustento y servicio al visitante, pero nunca deben convertirse en el motivo principal por el cual el turista visita el área. Generalmente se van agregando a posteriori en el destino para dar apoyo a los atractivos focales y complementarios que ya existen.

Aunque la jerarquización de los atractivos turísticos es, según Báez, y Acuña (2003), en última instancia, subjetiva y, por tanto, puede variar mucho dependiendo del interés, la educación y la inclinación de cada visitante, es preciso realizar un esfuerzo por identificar, analizar y clasificar de manera sistemática los atractivos turísticos del sitio o región correspondiente. La información y promoción turística deberá, en general, basarse en los atractivos focales. Tanto estos, como los complementarios, pueden existir o ser potenciales (en el caso de que actualmente no se encuentren accesibles). En cambio, los servicios de apoyo deberán estar presentes para poder comercializar el sitio.

Según Miller, 1980, en Báez y Acuña (2003), las etapas para realizar el inventario de los atractivos en un área protegida, puede sintetizarse de la manera siguiente:

- Familiarización con el área, estudiando los mapas existentes, la literatura, fotografías aéreas e imágenes satelitales y trabajando de conjunto con las personas con buenos conocimientos de la zona.

- Subdividir el área en unidades tipológicas en términos de problemas, usos y oportunidades particulares.

- Analizar y evaluar los lugares donde los problemas, usos y oportunidades de mayor prioridad requieren una decisión.

- Visitar los accesos y escalar las montañas para determinar visualmente las áreas de menos prioridad. Extrapolar la información y los criterios que se han establecido para los lugares que, debido a su baja prioridad, no serán visitados por el equipo.

- Reformular la información y los criterios recopilados en la revisión inicial.

Dentro de las lógicas limitaciones, deberán aprovecharse las facilidades actuales para la elaboración de una base de datos lo más completa posible de los atractivos turísticos del área y sus características particulares.

Por otro lado, con relación al procedimiento seguido en esta investigación, para alcanzar los objetivos propuestos, se realizó el levantamiento e inventario en el territorio de los atractivos incluidos en el Plan de Manejo, y, aplicando la técnica de la entrevista, se localizaron nuevos recursos con informantes clave de las comunidades cercanas al Parque, basándonos en la selección y evaluación realizada por los expertos mediante la aplicación del método Delphi. Además, también se amplió el estudio a otras localidades del Parque, cercanas a las ya registradas como de Uso Público, sin entrar en conflicto con las políticas de conservación ya aprobadas para el área protegida.

Se advierte aquí que existen metodologías de evaluación reconocidas a nivel mundial, como son las de la Organización de los Estados Americanos y la OMT (OEA, 1978; OMT, 1978), 
que también han servido de apoyo para esta investigación y, en cierta medida, minimizan la subjetividad del enfoque metodológico seleccionado. Por ello, bajo dicha premisa, se contemplaron factores tales como: el tipo de atractivo, localización, estado de los accesos, estado de conservación, existencia de especies endémicas de la flora y la fauna, cercanía a otros atractivos y actividades que podrían desarrollarse, porque no hay duda que, estos métodos de evaluación, independientemente de la carga de subjetividad que encierran, derivada del modo de su realización, permiten conocer, al menos de forma orientativa, el potencial del sitio para el uso público y su jerarquización, constituyendo una valiosa herramienta para dirigir las acciones encaminadas a la planificación y evaluación de estos atractivos.

En lo relativo a los atractivos, estos fueron clasificados usando la propuesta metodológica de SECTUR (2004), aunque modificada por los autores en: focales, los que presentan uno o varios de los factores antes mencionados, y que representan los rasgos esenciales que mejor caracterizan al sitio, o bien, aquellos que sin promoción reciben visitantes y, si todavía no los reciben, tienen posibilidades debido a su belleza y características singulares que le auguran un gran potencial, por lo que se le consideran como atractivos de primera categoría. Como atractivos complementarios, se clasificaron aquellos cuya belleza o características para su aprovechamiento son limitadas, o bien complementan la protección de los principales que cuentan con ciertas restricciones, ya sea por encontrarse en condiciones de fragilidad o en desventaja si recibieran un volumen considerable de personas, esto es, si su capacidad de carga es limitada. Asimismo, los complementarios permiten desarrollar actividades que refuerzan los atractivos focales.

Por último, en base a lo detectado en el inventario, y tras la jerarquización de los atractivos, el procedimiento seguido fue la identificación de las actividades de turismo de naturaleza más idóneas, dependiendo de las especificaciones técnicas requeridas para cada una de ellas. Cabe indicar que esta fase también tuvo su apoyo en diversos trabajos (Quesada de Castro, 2010; Ayala, 2007) que fueron analizados pensando en un segmento de mercado relacionado con el turismo de naturaleza, en montañas tropicales con cierto grado de dificultad en el acceso y tránsito. Ello, unido a la experiencia de los autores, permite inferir, a modo de avance, que las actividades más idóneas, a desarrollar en el área de estudio, son las siguientes: caminatas autoguiadas o con guías de la zona, observación de flora y vida silvestre (especialmente aves), observación del paisaje, en sitios seleccionados y miradores con infraestructura apropiada, o durante el tránsito por los senderos, agroturismo y turismo comunitario, asociado con la interacción con las comunidades que viven en el área o su entorno, turismo histórico-cultural relacionado con el conocimiento de la etapa revolucionaria en la zona (principales combates, etc.), baños en las pozas y saltos de agua existentes y turismo de aventura (escalada, etc.) entre otras.

\section{ATRACTIVOS TURÍSTICOS EN EL PARQUE NACIONAL PICO BAYAMESA}

El Parque Nacional Pico Bayamesa, localizado en la porción central de la Sierra Maestra, Cuba (ver figura 1). Posee una extensión superficial de $241 \mathrm{~km}^{2}$, de los cuales $197 \mathrm{~km}^{2} \mathrm{se}$ encuentran en la vertiente sur y solamente $44 \mathrm{~km}^{2}$ en la vertiente norte. El Pico Bayamesa, que da nombre al Parque, constituye su máxima altitud, con $1.752 \mathrm{~m}$., siendo una de las cinco 
mayores elevaciones del archipiélago cubano. La categoría de protección del Parque Nacional Pico Bayamesa es equivalente a la Categoría II de la UICN. El mismo, según Maceira, et al., (2005), conforma, junto al colindante Parque Nacional Turquino, el bloque montañoso por encima de los $1.200 \mathrm{~m}$ de altitud con mayor área en Cuba.

Estos dos Parques Nacionales poseen los valores de biodiversidad más altos de toda la Sierra Maestra, así como una flora y fauna de las más ricas de Cuba. Muchas de las especies restringidas a la sierra (anfibios, insectos, moluscos, helechos y arañas) se encuentran en esta área protegida. Once de las especies endémicas de aves de Cuba están presentes, a menudo, en números significativos (como el Tocororo y el Ruiseñor). El Parque también acoge importantes poblaciones de aves migratorias de Norteamérica, como la Bijirita Azul de Garganta Negra, y muchas especies vegetales y animales amenazados. Además de ríos y arroyos limpios y hermosas visuales desde sus numerosas alturas y miradores naturales.

En la zonificación propuesta para el Parque, se incluye la zona de uso público, que incluye importantes valores paisajísticos de biodiversidad y sitios históricos. Siendo la combinación de todo ello la que la hace especialmente atractiva para el desarrollo del turismo de naturaleza. No obstante, requiere estrategias de conservación y protección adecuadas para la puesta en valor turístico de su patrimonio histórico y natural.

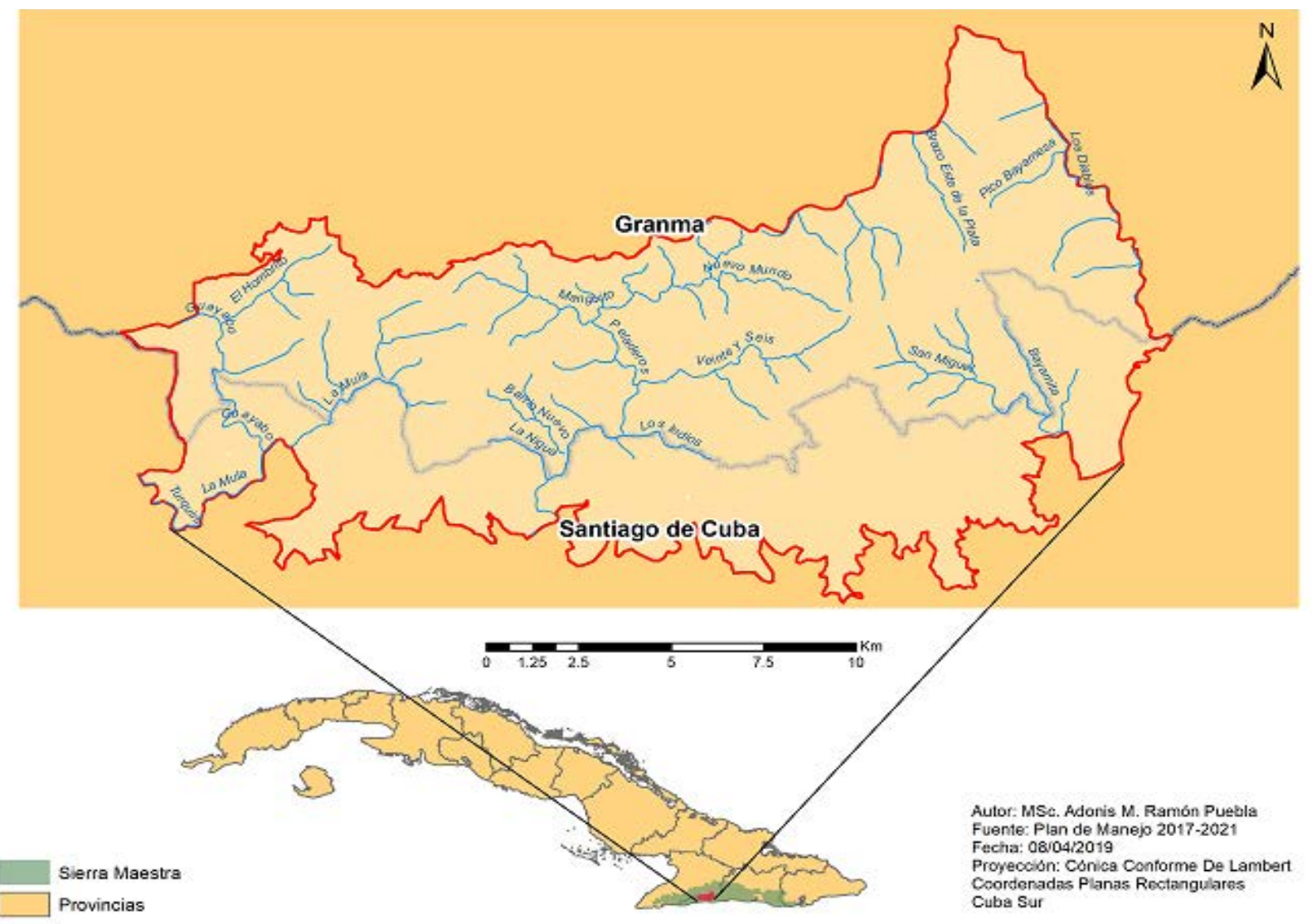

Figura 1. Localización del Parque Nacional Pico Bayamesa. Fuente: Elaborada por los autores. 


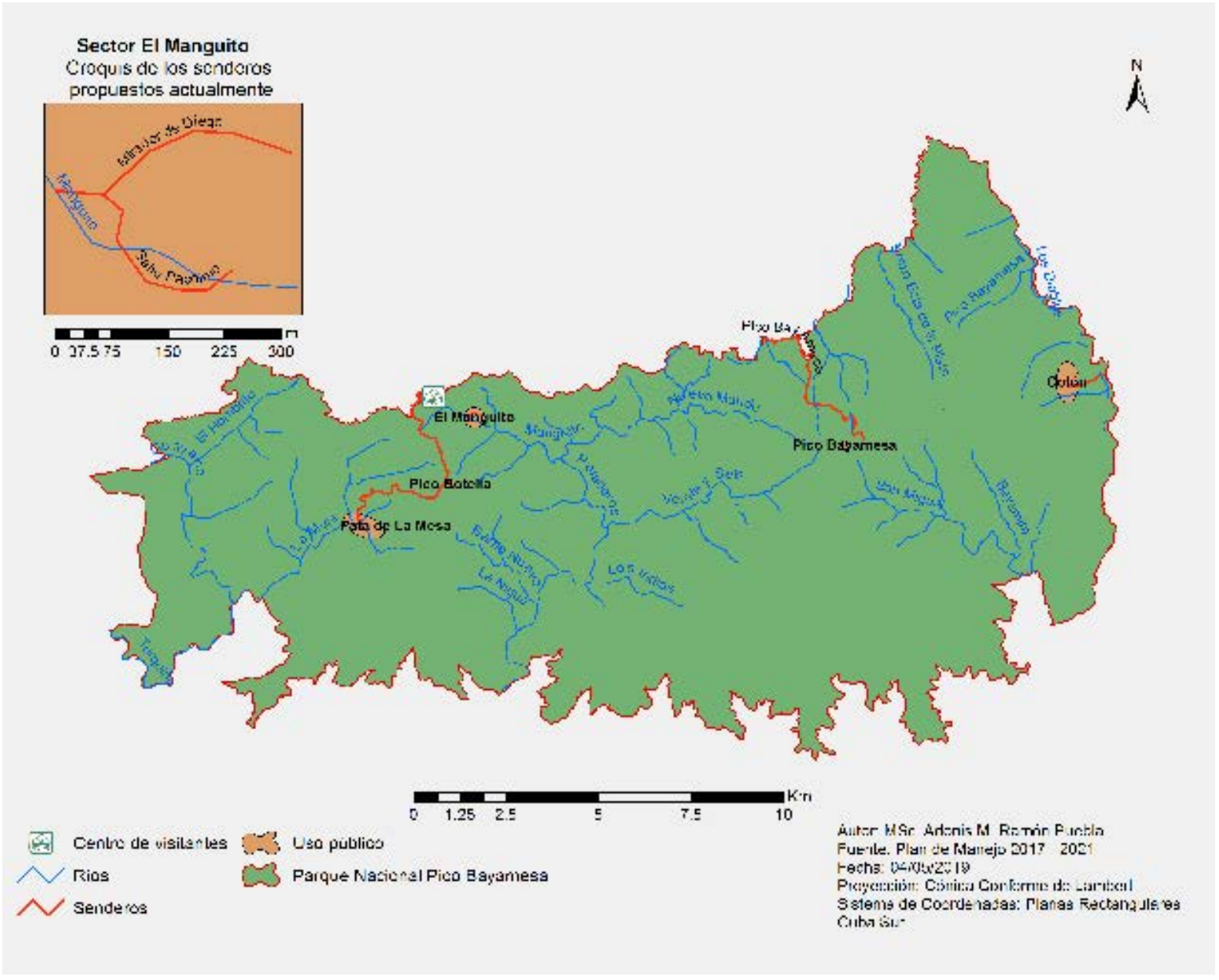

Figura 2. Propuesta de uso público del Parque Nacional Pico Bayamesa. Fuente: Elaborada por los autores a partir de información del Plan de Manejo 2017-2021

Esta zona (Ver figura 2), según Verdecia et al. (2006), abarca aproximadamente el $10 \%$ del área total del Parque, unos $14 \mathrm{~km}^{2}$, y posee muestras representativas de los valores presentes en la zona núcleo, estando la gestión de dichas áreas encaminada a facilitar el desarrollo de las actividades turísticas en sus más variadas formas, sin entrar en contradicción con los objetivos de la conservación del Parque. Siendo preciso, según los autores, cumplir las regulaciones técnicas para cada área, en cuanto a capacidad de carga y frecuencia de visitantes, entre otras.

Es necesario aclarar que, las zonas propuestas para uso público, son áreas despobladas del Parque, de propiedad estatal, gestionadas y administradas por la Empresa para la Protección de la Flora y la Fauna (rectora del mismo), a partir de un plan de manejo de estricto cumplimiento, lo que garantiza a futuro la preservación de los atractivos que se plantean incorporar a las propuestas turísticas dentro de la misma. En la Tabla 1 se sintetiza la propuesta de zonas de uso público con sus respectivos atractivos. 
Tabla 1. Atractivos turísticos incluidos en el Plan de Manejo del Parque Nacional Pico Bayamesa

\begin{tabular}{|c|c|c|}
\hline \multicolumn{3}{|c|}{ Zona de uso público Colón } \\
\hline Atractivo & Tipo & Actividades propuestas \\
\hline Poza La Redonda & Focal & $\begin{array}{l}\text { Baños en el río, observación del entorno } \\
\text { paisajístico }\end{array}$ \\
\hline \multicolumn{3}{|c|}{ Zona de uso público El Oro de Guisa } \\
\hline Atractivo & Tipo & Actividades propuestas \\
\hline Pico Bayamesa & Focal & $\begin{array}{l}\text { Ascenso al pico Bayamesa, observación del } \\
\text { entorno paisajístico }\end{array}$ \\
\hline \multicolumn{3}{|c|}{ Zona de uso público El Manguito } \\
\hline Atractivo & Tipo & Actividades propuestas \\
\hline Fuente de Ana & Focal & $\begin{array}{l}\text { Baños en el río, observación del entorno } \\
\text { paisajístico }\end{array}$ \\
\hline Salto Pacolmo & Focal & $\begin{array}{l}\text { Baños en el río, observación del entorno } \\
\text { paisajístico }\end{array}$ \\
\hline Mirador de Diego & Complementario & Observación del entorno paisajístico \\
\hline \multicolumn{3}{|c|}{ Zona de uso público Pata de la Mesa } \\
\hline Atractivo & Tipo & Actividades propuestas \\
\hline $\begin{array}{l}\text { Instalaciones de la } \\
\text { comandancia del Che en la } \\
\text { Sierra Maestra }\end{array}$ & Focal & $\begin{array}{l}\text { Recorrido histórico por las instalaciones de } \\
\text { la comandancia y observación del entorno } \\
\text { paisajístico. }\end{array}$ \\
\hline
\end{tabular}

Fuente: Plan de Manejo Parque Nacional Pico Bayamesa 2017-2021.

Como se observa, las citadas zonas de uso público propuestas, abarcan cuatro áreas que son:

- Colón, en el municipio de Guisa, donde el uso turístico propuesto es el Sendero a la Poza Redonda (ver figura 3), siendo su atractivo fundamental el baño en el río, en una poza, en un entorno visual muy agradable y pudiendo establecer una interacción con la comunidad. 


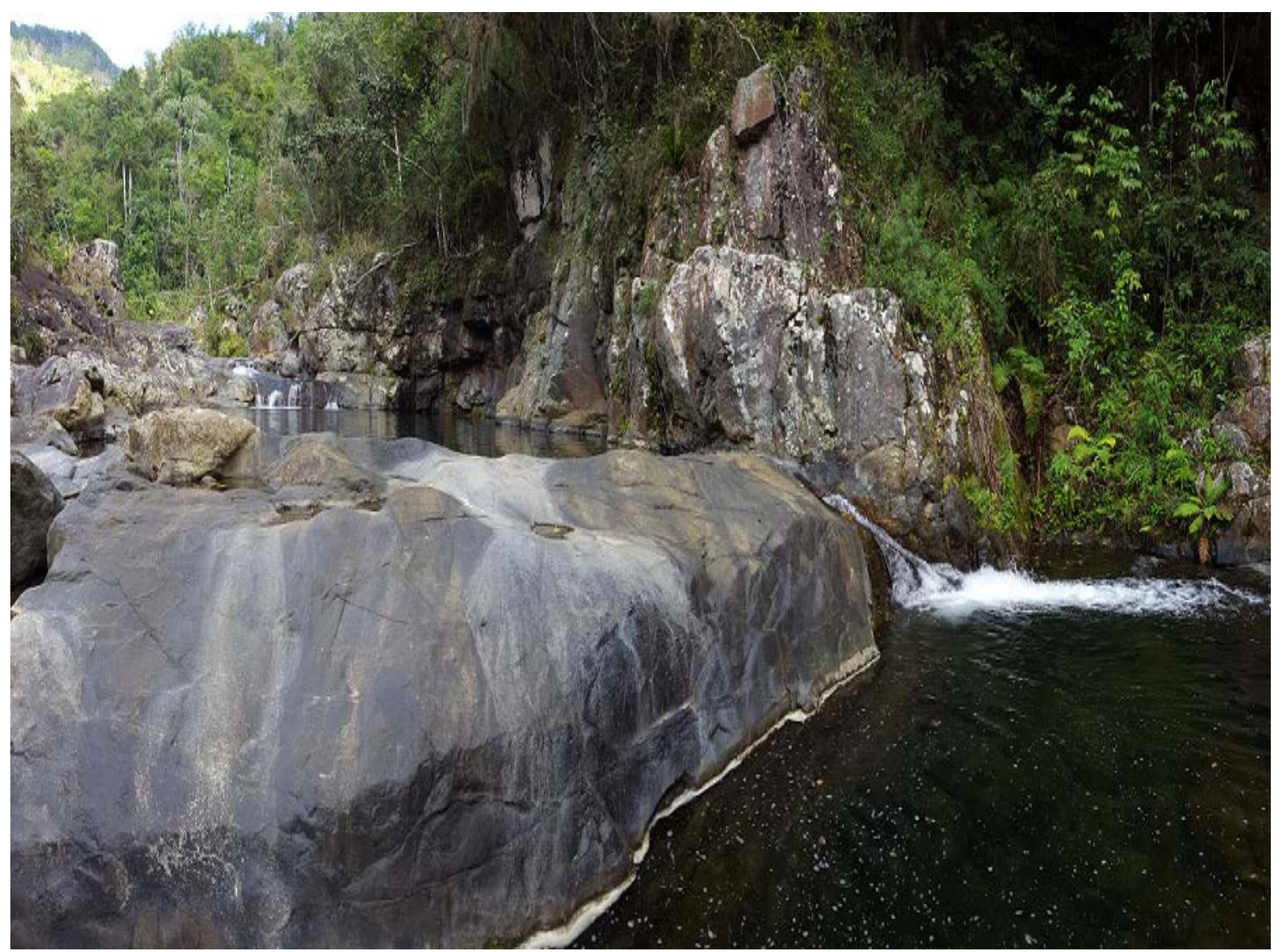

Figura 3. Poza Redonda, zona de uso público de Colón Autor: Adonis Ramón Puebla, 12/06/2019.

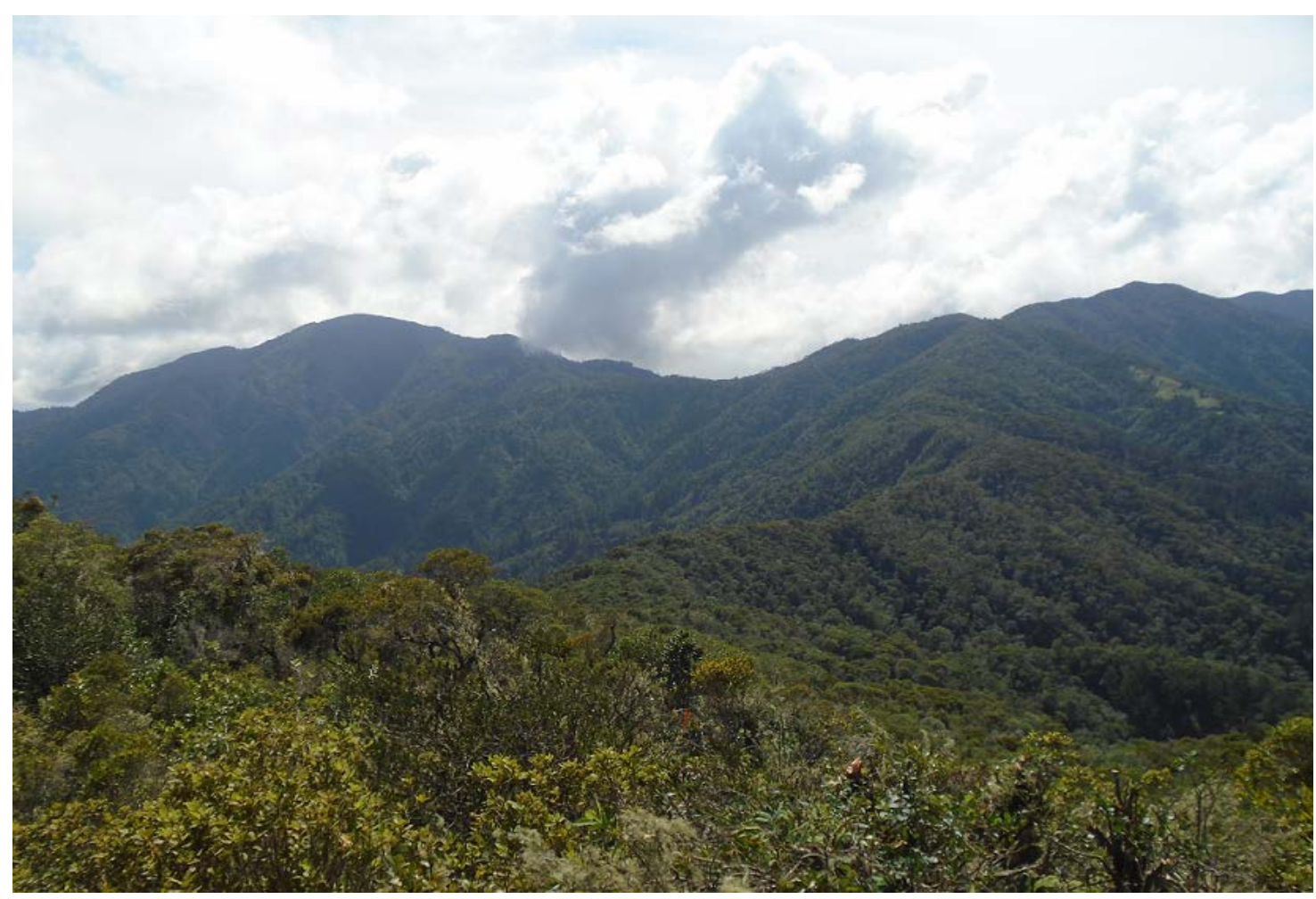

Figura 4. Sendero de ascenso al Pico Bayamesa. Autor: Adonis Ramón Puebla, 12/06/2019. 


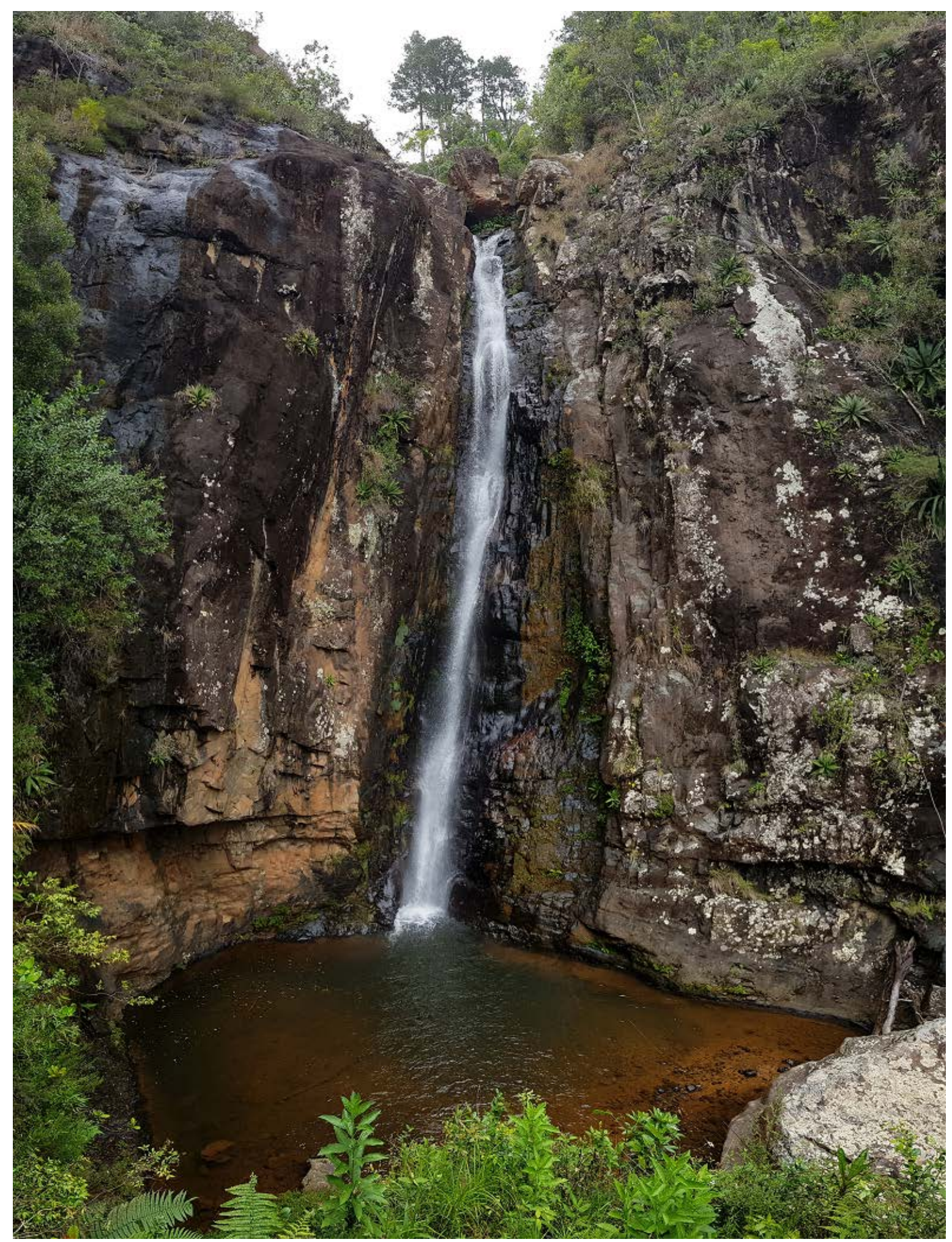

Figura 5. Sendero al salto Pacolmo (actual Salto El Manguito) Autor: Adonis Ramón Puebla, 12/06/2019.

- El Oro de Guisa, en el municipio de Guisa, para cuyo el uso turístico propuesto es el Sendero al Pico Bayamesa (ver figura 4), la mayor altura del Parque y una de las cinco 
mayores del país, como ya mencionamos, con una altitud de $1752 \mathrm{~m}$. sobre el nivel medio del mar, donde, además de disfrutar de excelentes visuales de 360 grados en su cima, se puede hacer observación de flora y fauna y los paisajes circundantes.

- El Manguito, en el municipio de Buey Arriba, con los senderos, Salto Pacolmo, Mirador de Diego, Fuente de Ana y ascenso hasta La Botella. Los tres primeros se encuentran en sitios cercanos, distantes unos pocos metros uno de otros en torno al río El Manguito y los saltos y pozas del mismo, de gran belleza (ver figura 5); así como un entorno visual muy agradable, lo que constituye el atractivo fundamental y el ultimo es un sendero de unos cientos de metros para ascender a la mayor elevación del territorio, cubierta de bosque pluvial montano con un nivel de conservación alto, en el cual el atractivo fundamental es la observación del paisaje y de aves durante el recorrido.

- Pata de la Mesa, en el municipio de Buey Arriba, el uso turístico propuesto es la visita al sitio donde estuvo enclavada la Comandancia de Ernesto Guevara (El Che) en la Mesa durante la época de los combates contra la dictadura de Batista (ver figura 6). El atractivo fundamental es histórico y en menor medida paisajístico; en este sitio se propone realizar un recorrido de varias horas por las instalaciones de la Comandancia del Che en la Sierra Maestra y revivir la historia y anécdotas del tiempo que fue usada como comandancia de la columna que dirigía el Che en la Sierra Maestra.

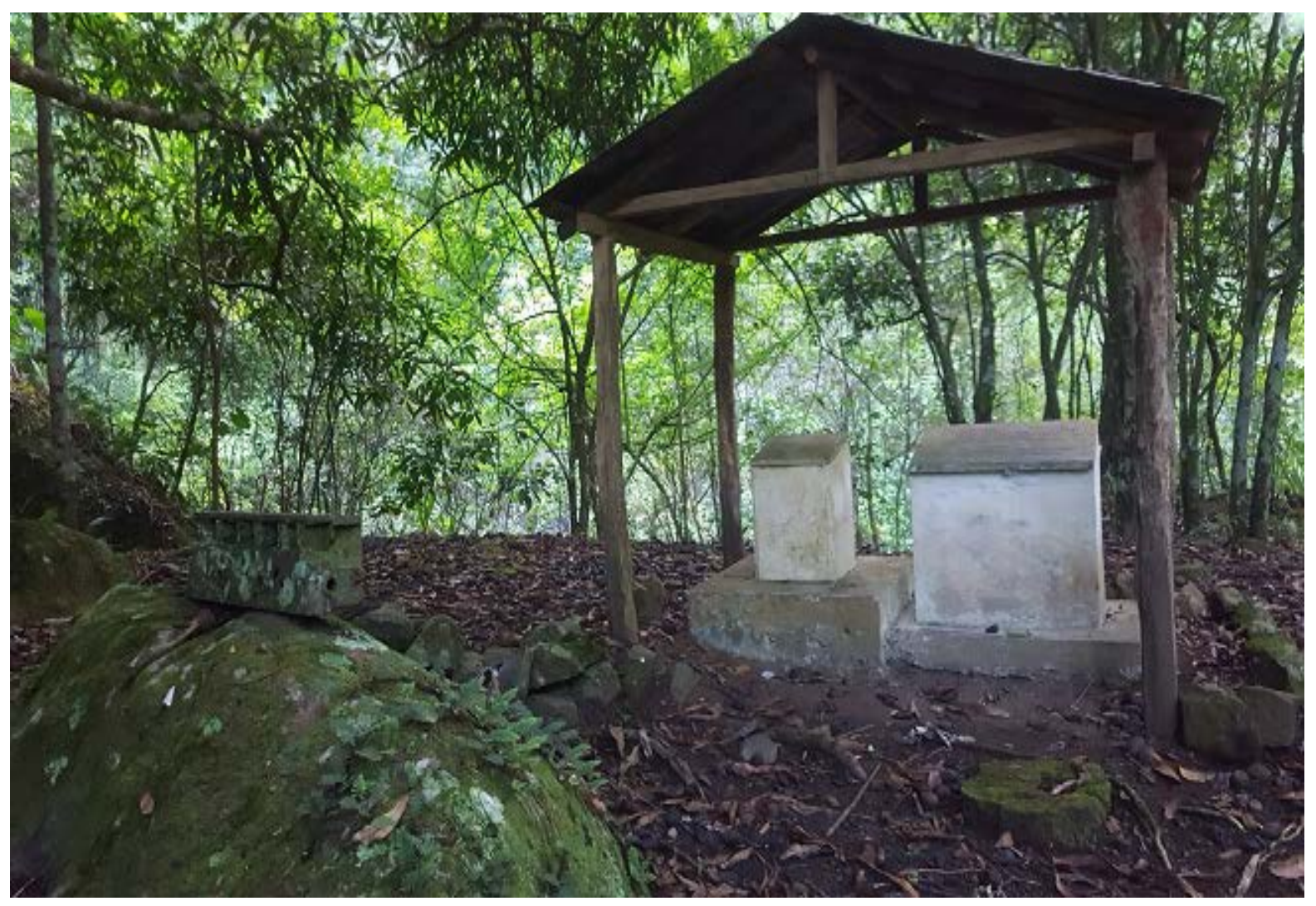

Figura 6. Una de las instalaciones de la Comandancia del Che en la Sierra Maestra, Pata de La Mesa. Autor: Adonis Ramón Puebla, 12/06/2019. 


\section{EVALUACIÓN DE LOS ATRACTIVOS Y PROPUESTAS TURÍSTICAS}

En toda evaluación y planificación de actividades turísticas en las áreas naturales protegidas, además de los requerimientos y limitaciones establecidas por su categoría de manejo, es indispensable realizar el inventario y jerarquización de los atractivos con potencial para el uso turístico, tanto los existentes como los potenciales. Esto debe llevarse a cabo de forma sistemática y detallada. Un inventario de atractivos turísticos no debe confundirse con un inventario científico de todas las especies de flora y fauna que se encuentran en la región, ni con el listado exhaustivo de todos los monumentos culturales o históricos de una localidad determinada. Más bien, este tipo de inventario, y de ahí la metodología utilizada en esta investigación, debe entenderse como la descripción ordenada y calificada de aquellos elementos que constituyen las principales atracciones y objetos de interés para los turistas potenciales (Báez y Acuña 2003) y para esto se puede emplear alguna de las metodologías más reconocidas a nivel mundial, como son las de la Organización de los Estados Americanos y la OMT (OEA, 1978; OMT, 1978), ya citadas en el apartado de metodología.

\section{V.1. Evaluación de los atractivos y propuestas turísticas por zonas de uso público}

Como ya se ha adelantado en el apartado de Metodología, el levantamiento e inventario se realizó en el campo, a partir de los atractivos presentes en el Plan de Manejo para cada zona de uso público; mientras que la localización de nuevos atractivos se realizó a partir de entrevistas con informantes clave de las comunidades cercanas, quienes facilitaron las referencias oportunas sobre aquellos sitios que podían ofrecer algún grado de atracción para los visitantes. También se amplió el estudio a otras localidades, cercanas a las actuales reconocidas como de Uso Público, sin entrar en conflicto con las políticas de conservación del área protegida y las zonas de conservación estrictas.

Posteriormente se realizó la evaluación de los atractivos según el tipo de atractivo, localización, estado y grado de dificultad del acceso, estado de conservación de los atractivos, existencia de especies endémicas de la flora y la fauna, cercanía a otros atractivos, estado del acceso desde el atractivo focal a los atractivos complementarios y tiempo de recorrido para acceder a estos. Este método de evaluación constituye una valiosa herramienta para dirigir las acciones encaminadas a la planificación y evaluación de los atractivos.

Asimismo, se evaluaron las actividades recreativas que pueden desarrollarse; sin dar, en esta ocasión un gran peso a los servicios de apoyo, ya que estos pueden ser agregados a posteriori dependiendo de las decisiones que se tomen al respecto, puesto que son inversiones que solo se realizarán después de una evaluación positiva para el desarrollo turístico de la zona en cuestión.

A continuación, se presenta, para cada zona de uso público del Parque Nacional Pico Bayamesa, la descripción y evaluación de los elementos antes señalados y, a la vez, a modo de síntesis se acompaña la Tabla 2:

- Colón, en el municipio de Guisa, a unos $50 \mathrm{~km}$ de la cabecera municipal, accesible para vehículos de doble tracción por un terraplén con fuertes pendientes y excelentes 
visuales de la zona montañosa, con unas cuatro horas de viaje, intransitable en algunas épocas del año por deslizamientos o lluvias. El atractivo focal son los baños en el río, en una poza, rodeada de vegetación boscosa, que se encuentra en un entorno visual muy agradable y permite la interacción con la comunidad. Los atractivos complementarios son varios saltos de agua, dispersos en la zona, con el inconveniente de que se encuentran alejados a más de 1 hora de recorrido desde el atractivo focal en diferentes direcciones y por accesos con pendientes de más de 20 grados de inclinación y no ofrecen un gran atractivo visual por si solos para convertirse en atractivos focales.

- El Oro de Guisa, en el municipio de Guisa, a unos 30 km de la cabecera municipal, accesible para vehículos de doble tracción por un terraplén que cruza el río en varias ocasiones y excelentes visuales de la zona montañosa, con un tiempo de viaje de aproximadamente 2 a 3 horas, dependiendo del estado del terraplén. El atractivo focal es escalar el Pico Bayamesa, la mayor altitud del Parque y una de las principales del país, además de disfrutar de una panorámica visual excelente en su cima de 360 grados, como atractivos complementarios están la observación de la flora, la fauna y los paisajes circundantes. Tiene limitaciones de acceso por ser un área de interés para la defensa del país, por lo cual queda excluido de cualquier propuesta de uso público desde la zona del Oro de Guisa.

- El Manguito, en el municipio Buey Arriba, distante unos $30 \mathrm{~km}$ de la carretera que conduce a la cabecera municipal, accesible para vehículos de doble tracción por un terraplén, con un tiempo de viaje de 2 a 3 horas y excelentes visuales de la zona montañosa durante todo el recorrido. Los atractivos focales, a partir de la zona que se propone como Centro de Visitantes son:

El salto El Manguito, a $2.3 \mathrm{~km}$ del Centro de visitantes, es un salto de agua del río del mismo nombre, con unos $35 \mathrm{~m}$ de caída libre, con excelentes visuales para su fotografía, que, a su vez, puede combinarse con otros atractivos complementarios, como La Fuente de Ana, una poza natural del rio con magnificas visuales del paisaje circundantes y otro número de pozas, no menos atractivas para la realización de baños. Todo el entorno está rodeado de bosque donde es posible la observación de aves y la flora del lugar y tiene como servicios de apoyo la existencia de miradores para la observación del salto, las pozas y las vistas circundantes, así como un sendero preparado para el acceso al atractivo principal y a los complementarios. Para estos atractivos se creó un grupo de senderos independientes, que conducen a cada uno de ellos, con la idea de comercializarlos por separado a pesar de encontrarse a pocos metros uno de otro y tener la posibilidad de vincularlos como un solo producto. Además, en esta misma área, durante la ejecución de esta investigación, se localizaron y sugirieron nuevos atractivos, que no están recogidos en el inventario del Plan de Manejo actual, distantes a $3 \mathrm{~km}$ del centro de visitantes y que se clasifican como complementarios. Tal fue el caso de 2 saltos de agua de 10 y 15 m respectivamente y, también, una elevación (la mayor de la zona de El Manguito) desde la que se pueden apreciar las elevaciones circundantes y todo el valle intramontano del río. Cabe señalar que, en dicha elevación, se construye actualmente un mirador. Se incluyen, además, varias pozas de profundidad y dimensiones variables, con la posibilidad de poder realizar la observación de flora y fauna del lugar. 
También destaca el Pico Botella, la mayor elevación de la zona y una de las más altas del Parque. Este se encuentra cubierto de bosque pluvial montano y se localiza a unos $3 \mathrm{~km}$ de la zona de El Manguito, siendo accesible desde el mismo por un camino en buenas condiciones, sombreado por bosques de pinos y excelentes visuales de las mayores elevaciones de Cuba al llegar al terraplén que va desde el Centro de visitantes propuesto a la antigua comunidad de Barrio Nuevo. Como atractivos complementarios, encontramos las visuales durante el recorrido y la observación de aves y flora.

Asimismo, es relevante la Comandancia del Che en La Mesa, distante unos $7 \mathrm{~km}$ del Centro de Visitantes, que tiene como atractivos focales, las instalaciones del lugar, la historia de la misma y las pozas llamadas Las Piscinas de Polo. Mientras que, como atractivos complementarios, están las visuales durante el recorrido, la observación de aves y flora y disfrutar de un baño en las pozas donde se bañaba el Che. La propuesta actual, de uso público hacia la zona, es un recorrido por las instalaciones de la Comandancia del Che.

Tabla 2. Evaluación de los atractivos turísticos del Parque Nacional Pico Bayamesa con los nuevos atractivos estudiados

\begin{tabular}{|c|c|c|c|c|c|c|c|}
\hline \multicolumn{8}{|c|}{ Zona de uso público Colón } \\
\hline Atractivo & Tipo & $\begin{array}{l}\text { Estado de } \\
\text { conservación }\end{array}$ & $\begin{array}{l}\text { Existencia } \\
\text { de especies } \\
\text { endémicas }\end{array}$ & $\begin{array}{l}\text { Cercanía } \\
\text { a otros } \\
\text { atractivos }\end{array}$ & $\begin{array}{l}\text { Estado del } \\
\text { acceso al } \\
\text { atractivo } \\
\text { y grado de } \\
\text { dificultad }\end{array}$ & $\begin{array}{l}\text { Tiempo de re- } \\
\text { corrido desde } \\
\text { el atractivo } \\
\text { focal }\end{array}$ & $\begin{array}{l}\text { Evaluación } \\
\text { general }\end{array}$ \\
\hline $\begin{array}{l}\text { Poza La Re- } \\
\text { donda }\end{array}$ & Focal & Bueno & $\mathrm{Si}$ & Media & $\begin{array}{l}\text { Malo, } \\
\text { fuertes pen- } \\
\text { dientes }\end{array}$ & - & Buena \\
\hline $\begin{array}{l}\text { *Salto Mu- } \\
\text { jeres }\end{array}$ & Complementario & Bueno & $\mathrm{Si}$ & Media & $\begin{array}{l}\text { Malo, } \\
\text { fuertes pen- } \\
\text { dientes }\end{array}$ & 1.5 horas & Regular \\
\hline *Salto La Bota & Complementario & Bueno & $\mathrm{Si}$ & Media & $\begin{array}{l}\text { Malo, } \\
\text { fuertes pen- } \\
\text { dientes }\end{array}$ & 1.5 horas & Regular \\
\hline \multicolumn{8}{|c|}{ Zona de uso público El Oro de Guisa } \\
\hline Atractivo & Tipo & $\begin{array}{l}\text { Estado de } \\
\text { conservación }\end{array}$ & $\begin{array}{l}\text { Existencia } \\
\text { de especies } \\
\text { endémicas }\end{array}$ & $\begin{array}{l}\text { Cercanía } \\
\text { a otros } \\
\text { atractivos }\end{array}$ & $\begin{array}{l}\text { Estado del } \\
\text { acceso al } \\
\text { atractivo } \\
\text { y grado de } \\
\text { dificultad }\end{array}$ & $\begin{array}{l}\text { Tiempo de re- } \\
\text { corrido desde } \\
\text { el atractivo } \\
\text { focal }\end{array}$ & $\begin{array}{l}\text { Evaluación } \\
\text { general }\end{array}$ \\
\hline Pico Bayamesa & Focal & Bueno & $\mathrm{Si}$ & No & $\begin{array}{l}\text { Malo, } \\
\text { fuertes pen- } \\
\text { dientes }\end{array}$ & - & Buena \\
\hline
\end{tabular}




\begin{tabular}{|c|c|c|c|c|c|c|c|}
\hline \multicolumn{8}{|c|}{ Zona de uso público El Manguito } \\
\hline Atractivo & Tipo & $\begin{array}{l}\text { Estado de } \\
\text { conservación }\end{array}$ & $\begin{array}{l}\text { Existencia } \\
\text { de especies } \\
\text { endémicas }\end{array}$ & $\begin{array}{l}\text { Cercanía } \\
\text { a otros } \\
\text { atractivos }\end{array}$ & $\begin{array}{l}\text { Estado del } \\
\text { acceso al } \\
\text { atractivo } \\
\text { y grado de } \\
\text { dificultad } \\
\end{array}$ & $\begin{array}{l}\text { Tiempo de re- } \\
\text { corrido desde } \\
\text { el atractivo } \\
\text { focal }\end{array}$ & $\begin{array}{l}\text { Evaluación } \\
\text { general }\end{array}$ \\
\hline $\begin{array}{l}\text { Salto Pacolmo } \\
\text { (El Manguito) }\end{array}$ & Focal & Bueno & $\mathrm{Si}$ & $\mathrm{Si}$ & \begin{tabular}{|l} 
Regular, \\
pendientes \\
medias \\
\end{tabular} & - & Muy buena \\
\hline Fuente de Ana & Focal & Bueno & $\mathrm{Si}$ & $\mathrm{Si}$ & \begin{tabular}{|l} 
Regular, \\
pendientes \\
medias
\end{tabular} & - & Muy buena \\
\hline $\begin{array}{l}\text { Mirador de } \\
\text { Diego }\end{array}$ & Complementario & Bueno & Si & $\mathrm{Si}$ & $\begin{array}{l}\text { Regular } \\
\text { pendientes } \\
\text { medias }\end{array}$ & $>15$ minutos & Muy Buena \\
\hline $\begin{array}{l}\text { *Mirador El } \\
\text { Manguito }\end{array}$ & Complementario & Bueno & Si & Si & \begin{tabular}{|l} 
Regular, \\
pendientes \\
medias \\
\end{tabular} & $>30$ minutos & Muy buena \\
\hline $\begin{array}{l}\text { *Salto La Bo- } \\
\text { tella }\end{array}$ & Complementario & Bueno & $\mathrm{Si}$ & $\mathrm{Si}$ & \begin{tabular}{|l} 
Regular \\
pendientes \\
medias \\
\end{tabular} & $>50$ minutos & Muy buena \\
\hline $\begin{array}{l}\text { *Salto El To- } \\
\text { rito }\end{array}$ & Complementario & Bueno & Si & $\mathrm{Si}$ & \begin{tabular}{|l} 
Regular, \\
pendientes \\
medias \\
\end{tabular} & $>40$ minutos & Muy buena \\
\hline $\begin{array}{l}\text { *Pocetas ar- } \\
\text { royo La Botella }\end{array}$ & Complementario & Bueno & $\mathrm{Si}$ & $\mathrm{Si}$ & \begin{tabular}{|l} 
Regular, \\
pendientes \\
medias \\
\end{tabular} & $>30$ minutos & Muy buena \\
\hline $\begin{array}{l}\text { *Pocetas río } \\
\text { Nuevo Mundo }\end{array}$ & Complementario & Bueno & $\mathrm{Si}$ & $\mathrm{Si}$ & \begin{tabular}{|l} 
Regular, \\
pendientes \\
medias
\end{tabular} & $>30$ minutos & Muy buena \\
\hline Pico Botella & Focal & Bueno & Si & $\mathrm{Si}$ & \begin{tabular}{|l} 
Regular, \\
pendientes \\
medias \\
\end{tabular} & 1 hora & Buena \\
\hline \multicolumn{8}{|c|}{ Zona de uso público Pata de la Mesa } \\
\hline Atractivo & Clasificación & $\begin{array}{l}\text { Estado de } \\
\text { conservación }\end{array}$ & $\begin{array}{l}\text { Existencia } \\
\text { de especies } \\
\text { endémicas }\end{array}$ & $\begin{array}{l}\text { Cercanía } \\
\text { a otros } \\
\text { atractivos }\end{array}$ & \begin{tabular}{|l} 
Estado de \\
acceso al \\
atractivo \\
y grado de \\
dificultad \\
\end{tabular} & $\begin{array}{l}\text { Tiempo de } \\
\text { recorrido } \\
\text { desde atracti- } \\
\text { vo focal }\end{array}$ & $\begin{array}{l}\text { Evaluación } \\
\text { general }\end{array}$ \\
\hline $\begin{array}{l}\text { Instalaciones } \\
\text { Comandancia } \\
\text { del Che en la } \\
\text { Sierra Maestra }\end{array}$ & Focal & Regular & $\mathrm{Si}$ & $\mathrm{Si}$ & Bueno & $\begin{array}{l}\text { El recorrido } \\
\text { por todas las } \\
\text { instalaciones } \\
\text { es de unas } 3 \\
\text { horas. }\end{array}$ & Regular \\
\hline $\begin{array}{l}\text { Pocetas Pisci- } \\
\text { nas de Polo }\end{array}$ & Complementario & Bueno & $\mathrm{Si}$ & No & Bueno & 5 minutos & Muy buena \\
\hline
\end{tabular}

Fuente: Elaborada por los autores a partir del Plan de Manejo 2017-2021 y de los recorridos de campo. Nota los atractivos señalados con asterisco, fueron identificados y evaluados en el trabajo de campo. 


\section{PROPUESTA DE USO PÚBLICO EN EL PARQUE NACIONAL PICO BAYAMESA}

Después de ser identificadas y evaluadas, como consta en la Tabla 2, aquellas áreas propuestas como de uso público, a partir, en primer lugar, de contar con atractivos turísticos suficientes (en términos de calidad, cantidad y distancia entre estos) para justificar el desarrollo de la actividad, se consideró, en segunda instancia, a juicio de los autores y expertos consultados, que estas áreas debían contar también con otras condiciones como: accesibilidad, calidad del acceso a los atractivos, infraestructura básica, distancia a posibles centros emisores de visitantes e inexistencia de limitaciones legales.

Por todo ello se propuso realizar modificaciones a la propuesta de áreas de uso público, actualmente existente, con el fin de que puedan ser incorporadas al próximo Plan de Manejo para el periodo 2022-2026.

Finalmente, cabe acotar que, esta propuesta de reorganización de la zona de uso público, está integrada a la zonificación del área en general y es compatible con los objetivos planteados para las demás zonas de manejo del área protegida, como no podría ser de otro modo si lo que se pretende es llevar a cabo una adecuada planificación de estos espacios. En el mapa de la figura 7 se ilustra cómo quedaría la zona de uso público a partir de esta nueva propuesta.

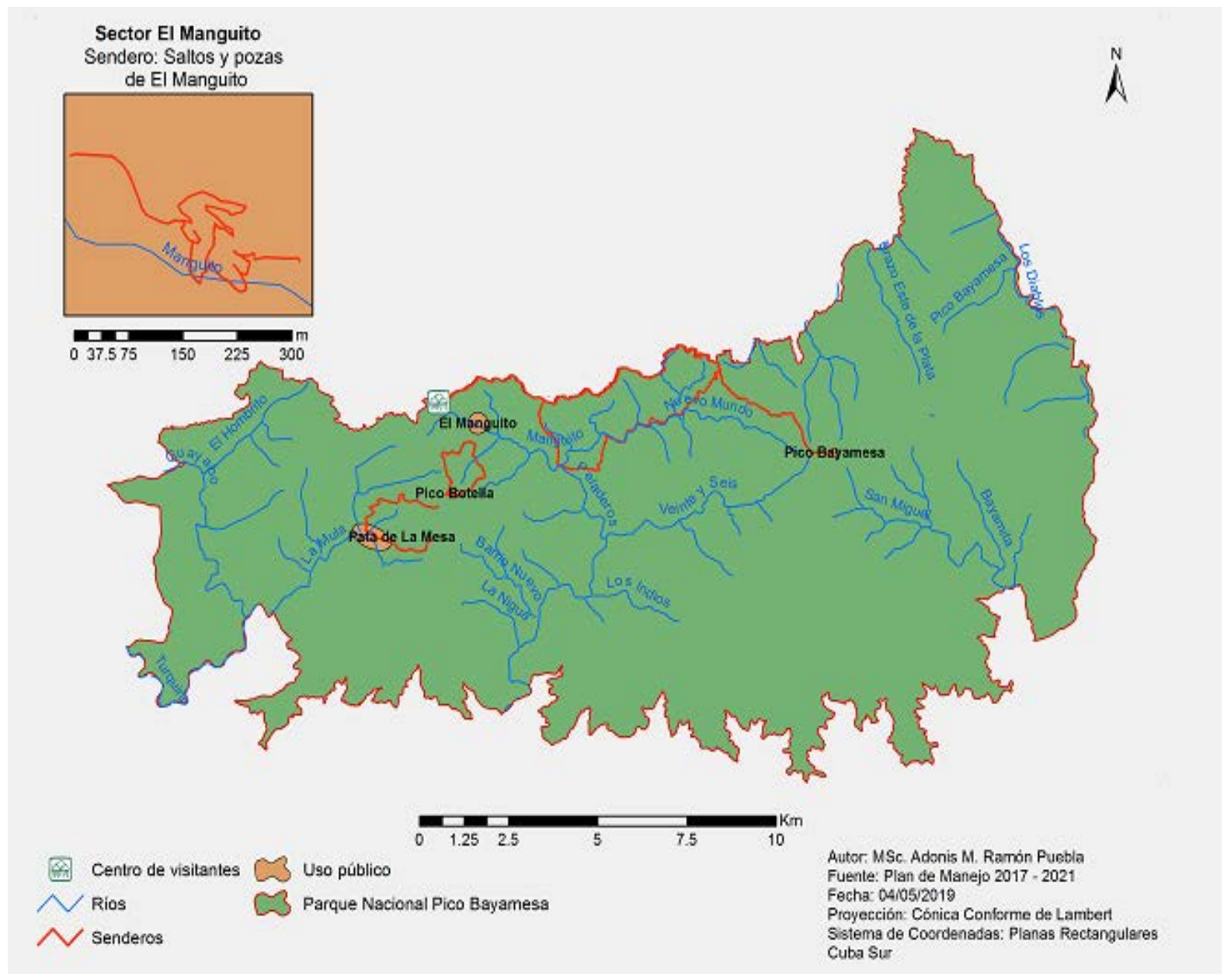

Figura 7. Nueva propuesta de uso público del Parque Nacional Pico Bayamesa. Fuente: Elaborada por los autores 


\section{VI.1. Zonas de uso público propuestas y modificaciones de las existentes.}

- Colón, distante unos $70 \mathrm{~km}$ de la cabecera municipal, con dificultades de acceso, viales en mal estado, problemas de derrumbes en épocas de lluvias, poca importancia del atractivo focal por sí solo y su lejanía a otros atractivos secundarios identificados en la zona. Se propone eliminarla como zona de uso público y mantener el acceso al rio para actividades veraniegas de la comunidad cercana, que siempre usó la poza del río con esta finalidad.

- El Oro de Guisa, separado unos $30 \mathrm{~km}$ de la cabecera municipal, con viales en estado regular, que tiene como limitante el acceso a la comunidad del Oro de Guisa desde donde parte el sendero propuesto. Esta limitación obliga a transitar por zonas con restricciones legales, que son de interés para la defensa del país y, por tanto, exige excluir de cualquier propuesta de uso público la zona circundante a la localidad del Oro de Guisa y el acceso a la misma. Sin embargo, esto no ocurre con la cima del Pico La Bayamesa, ni con el camino de acceso al mismo, que pueden, por lo tanto, ser integrados mediante accesos existentes al sector El Manguito.

- El Manguito, se puede considerar como el principal sitio para el uso público dentro del Parque. No obstante, para un uso más efectivo, y que aproveche la totalidad de los potenciales de esta área del Parque, se requiere modificar los límites de la zona de uso público a expensas de zonas propuestas actualmente para la conservación, sin que esta modificación afecte zonas importantes para la flora y fauna o de conservación estricta. Estas zonas que se pretenden anexar a la de uso público existente, coinciden con otras que presentan alteraciones de origen antrópico, puesto que están cercanas a una pequeña comunidad y solo se afectarían los accesos existentes por las obras para el mejoramiento de los caminos para acceder a los nuevos atractivos identificados. Por otro lado, se propone la unión y modificación de varias de las propuestas de senderos existentes, que todavía no han sido aprobados legalmente, para unir el atractivo focal de esta zona con los complementarios en un solo recorrido, mientras que, en la propuesta actual, consta de 3 senderos, uno al atractivo focal y otros a los secundarios de forma independiente.

- Sendero Saltos y pozas de El Manguito, se propone, partiendo del centro de visitantes, vincular los tres senderos existentes: Salto Pacolmo (El Manguito), Fuente de Ana y Mirador de Diego como un solo producto, aprovechando los accesos existentes y realizar un recorrido circular que incluya todos estos atractivos, más un trayecto por un sector del río con excelentes visuales, otros saltos de menor tamaño y pozas, así como la posibilidad de visitar no solo la base del salto, sino también su punto de caída, disfrutar de la flora y fauna del lugar y baños en el río. Con este propósito, se requiere el mantenimiento de la infraestructura existente y el mejoramiento en el acceso a los nuevos atractivos a incluir en el recorrido.

Para los nuevos atractivos que fueron inventariados: dos saltos de agua de 10 y 15 $m$ de altura respectivamente, una elevación (la mayor en la zona de El Manguito, en la cual está previsto construir una torre de observación) y un sector del río y pozas de profundidad y dimensiones variables, se propone un nuevo sendero circular que vincule todos estos atractivos, incluyendo la observación de paisajes y aves, así como el recorrido por un sector del río 
y baños en el mismo. Para este fin, es necesaria la construcción de toda la infraestructura, accesos, miradores y facilidades en los senderos.

- En el caso de Pico Botella, se propone un sendero pedestre desde la comunidad El Manguito a esta elevación, cubierta de bosques pluviales montanos, en la cual se construye un mirador que, por encima del dosel de la vegetación, posibilitará una visual del paisaje de 360 grados, disfrutar de la vista del Pico Turquino (la mayor elevación de Cuba) y otras elevaciones desde el camino, así como la observación de aves y la flora durante el recorrido. Se requiere, para ello, mejorar los accesos al Pico La Botella y terminar el mirador en su cima.

- Para la Comandancia del Che en La Mesa, se presenta la propuesta de una nueva ruta de acceso, con menos pendiente y más corta, para acceder a la misma, así como otra de salida para evitar la monotonía de un descenso y ascenso con bastante dificultad hacia y desde el alto a la Comandancia de casi cuatro kilómetros por la misma ruta. Asimismo, debe establecerse la vinculación de la historia con el disfrute de un baño en el río en las llamadas Piscinas de Polo. Para ello, es preciso sustituir las tarjas e instalaciones actuales por otras que recuperen el diseño original de las instalaciones, además del reacondicionamiento de los accesos entre las instalaciones y hacia la Comandancia.

- En Pico Bayamesa, a partir de antiguos accesos que comunican la zona de El Manguito con esta elevación, se propone una ruta de acceso pedestre con dos noches, una a la ida y otra al regreso, para visitar una de las principales elevaciones del país y la mayor del Parque que da nombre al misma. Se plantea la ida por la zona limítrofe del área protegida, lo que posibilitará disfrutar de excelentes vistas, la flora y la fauna, y el regreso por un camino que bordea el rio Nuevo Mundo, donde existe la posibilidad de disfrutar de pequeños saltos, pozas y baños en el río, además de observar la flora y fauna del lugar.

\section{CONCLUSIONES}

El trabajo realizado en el Parque Nacional Pico Bayamesa, a partir de la aplicación de los criterios recogidos por la metodología de Báez y Acuña (2003), más otros criterios incluidos por los autores, a partir de la experiencia de su implementación, permitió la evaluación de atractivos en áreas protegidas de Cuba.

Cabe destacar que se trata de la primera vez que esta metodología se aplica en el país, que los resultados obtenidos han sido muy bien valorados y que se han considerado de muy fácil implementación. Es, precisamente, esta valoración y la posibilidad de aplicar este método de análisis en otras áreas protegidas del país, lo que permite apreciar su validez y el interés para los propios espacios naturales que, sin un adecuado inventario y valoración de sus atractivos naturales e histórico-culturales no cuentan con la clasificación de categorías de Uso Público y, por tanto, de ofertas adecuadas, que sean atractivas a los potenciales clientes y respetuosas con los valores ambientales de esas áreas.

Sin duda, puede concluirse que se ha realizado el principal objetivo propuesto para esta investigación, inventariando y evaluando los recursos paisajísticos e históricos del Parque 
Nacional Pico Bayamesa. Asimismo, se han llevado a cabo los tres objetivos específicos, fundamentalmente planteados a partir del Plan de Manejo 2017-2021 y concretado en la nueva propuesta que se consigue una vez identificados y clasificados los atractivos que pretenden incorporarse de cara al futuro Plan de Manejo. En este sentido, la evaluación de la propuesta actual de uso público existente en el Plan de Manejo 2017-2021, permitió establecer recomendaciones para la inclusión de algunos atractivos nuevos, cambios en dichas áreas y las actividades a desarrollar para el turismo de naturaleza, buscando la viabilidad de las mismas. Entre las propuestas realizadas destacan las siguientes:

- El acceso a las áreas correspondientes al Oro de Guisa por el sendero a Pico La Bayamesa es inoperante por limitaciones de carácter legal, planteándose la eliminación de este sector como uso público, no así del acceso al Pico La Bayamesa.

- El área que esta propuesta en la localidad de Colón no contiene la cantidad ni calidad de atractivos que justifiquen un trayecto de varias horas para su visita, además de la dispersión de los pocos atractivos complementarios que se identificaron y la distancia entre estos, proponiéndose eliminar este sector dentro de la zona de uso público.

- La localidad del Manguito, es la que presenta el mayor número de atractivos de carácter focal y complementario, posibilitando la realización de varios recorridos, por lo que se propone que esta sea la zona hacia la cual se encaminen todos los esfuerzos de desarrollo, y la modificación de sus límites dentro de la zona de uso público.

En definitiva, puede argumentarse que, a lo largo de esta investigación, partiendo de un método cualitativo descriptivo, se ha procurado, mediante la aplicación de parámetros ya establecidos en otros trabajos y la propia observación, en el territorio caso de estudio, encontrar explicaciones que pueden mejorar las condiciones del Uso Público y, asimismo, servir de referente para otros espacios naturales de Cuba que no han sido evaluados todavía.

\section{REFERENCIAS BIBLIOGRÁFICAS}

Antón, S., Blay, J. y Salvat, J. (2008). Turismo, actividades recreativas y uso público en los parques naturales. Propuesta para la conservación de los valores naturales ambientales y el desarrollo productivo local. Boletín de la Asociación de Geógrafos Españoles, (48) 5-38.

APN (2001). Plan de Gestión Institucional para los Parques Nacionales, Argentina, 74 pp.

Arellano-Guillermo, A., M. C.; García-Rivas, O.; Álvarez-Gil y J. Acosta-Aburto (2005). Manual de Métodos para la Elaboración de Programas de Uso Público en Áreas Protegidas de la región del SAM.

Artigues-Bonet, A. A. y M. Blázquez-Salom (2016). Huidas al paraíso y la realización mercantil del sueño, XIV Coloquio Internacional de Geocrítica Las utopías y la construcción de la sociedad del futuro Barcelona, 2-7 de mayo de 2016, Barcelona Geocritica, 12 pp.

Ayala, H. (Coord.) (2007). Modalidades turísticas. Características y situación actual, Universidad de La Habana, 314 pp.

Balmford, A.; Green, J.M. H.; Anderson, M.; Beresford, J.; Huang, C.; et al. (2015). Walk on the Wild Side: Estimating the Global Magnitude of Visits to Protected Areas. PLOS Biology 13 (2)): e1002074. Recuperado de: https://doi.org/10.1371/journal.pbio.1002074 
Báez, A y Acuña, A. (2003). Guía para las mejores prácticas de ecoturismo en áreas protegidas, Comisión Nacional para el Desarrollo de los Pueblos Indígenas, México, DF, 152 pp.

Blázquez. M. (2005). Uso público del patrimonio natural en Maestría de Gestión Turística, Universidad Internacional de Andalucía, La Rábida, España, 25 pp.

Booth, J. E.; Gaston, K. J. and Armsworth, P. R. (2010). Who benefits from recreational use of protected areas? Ecology and Society 15 (3) 19. Recuperado de: http://www.ecologyandsociety.org/vol15/iss3/art19/

Bushell, R.; Eagles, P. F. J. (2007). Tourism and Protected Areas. Benefits Beyond Boundaries, CAB International, UK, 349 pp.

Cebrián, F. y Sánchez, J. (2015). Turismo de naturaleza en Áreas protegidas de México; una propuesta de conservación, aprovechamiento y desarrollo local en el nevado de Toluca, Cuadernos de Turismo, (36) 339-365.

Centro Nacional de Áreas Protegidas. (2013). Plan del Sistema Nacional de Áreas Protegidas 2014-2020, Ministerio de Ciencias Tecnología y Medio Ambiente, la Habana, Cuba. 366 pp.

CONANP (2006). Estrategia Nacional para un Desarrollo Sustentable del Turismo y la Recreación en las ANP de México, Programa de Turismo en ANP 2006 - 2012.

Centeno, J. C. y De la Garza, D. J. (2014). Observación. En Sáenz, K. y Tamez, G. (Coord.) Métodos y técnicas cualitativas y cuantitativas aplicables a la investigación en ciencias sociales. Tirant Humanidades. México.

Díaz, L. (2011). La observación. México: Facultad de Psicología. UNAM.

Eagles, P. F. J.; Mccool, S. F.; Haynes, C. D. A. (2002). Sustainable tourism in protected areas: guidelines for planning and management, IUCN Gland, Cambridge, 183, pp.

EUROPARC-España (2002). Plan de Acción para los espacios naturales protegidos del Estado Español, Editorial Fundación Fernando González Bernáldez, 165 pp.

EUROPARC-España (2005). Conceptos de uso público en los espacios naturales protegidos, Editorial Fundación Fernando González Bernáldez. Madrid, 94 pp.

EUROPARC-España (2018). Especial 25 aniversario. Revista técnica de los espacios protegidos, Boletín 46 (diciembre de 2018). Recuperado de http://www.redeuroparc.org/system/ files/shared/Publicaciones/Boletines/boletin46.pdf

Fontoura, L. M., De Medeiros, R. J., y Adams, L. W. (2016). Turismo, pressões e ameaças para a conservação da biodiversidade em parques nacionais do Brasil e Estados Unidos, CULTUR, ano 10 (01) 35-53.

Garzón, R. y E., Arias (2008). La planificación y ordenación del uso público en espacios protegidos andaluces: contextualización general y estudio específico en el Parque Natural Sierra Norte de Sevilla, Cuadernos de Turismo, (21) 33-65.

Garzón, R. y M. L. Ramírez (2018). Las áreas protegidas como territorios turísticos: análisis crítico a partir del caso de los Parques Naturales de la Sierra Morena Andaluza, Cuadernos de Turismo, (41) 249-277.

Gerhartz, J.; R. Estrada; E. Hernández; A. Hernández y A. González (2007). Metodología para la Elaboración de los Planes de Manejo de las Áreas Protegidas de Cuba, Editorial Feijóo, Centro Nacional de Áreas Protegidas de Cuba, La Habana, 103 pp. 
Gómez-Limón, J. y García, D. (2014). Capacidad de acogida de uso público en los espacios naturales protegidos. Cuadernos de la Red de Parques Nacionales 3. Organismo Autónomo Parques Nacionales.

Hernández de la Obra, J. y Gómez-Limón, J. (2005). Manual sobre conceptos de uso público en los espacios naturales protegidos. Madrid, Fundación Fernando González Bernáldez, $94 \mathrm{pp}$.

Hiernaux, D. (2008). Una década de cambios: la Geografía Humana y el estudio del Turismo. Scripta Nova, Revista Electrónica de Geografía y Ciencias Sociales. Universidad de Barcelona. Vol. XII, núm. 270 (87).

IUCN. (1994). Guidelines for Protected Area Management categories. CNPPA and WCMC. IUCN, Gland, Suiza y Cambridge, UK.

Leung, Yu-Fai; Spenceley, A.; Hvenegaard, G. y Buckley, R. (eds.) (2019). Gestión del turismo y de los visitantes en áreas protegidas: directrices para la sostenibilidad, Serie Directrices sobre Buenas Prácticas en Áreas Protegidas 27, Gland, Suiza: UICN,120 pp.

Maceiras, D., A; Fong, W. Alverson; Watcher, T. (2005). Cuba: Parque Nacional La Bayamesa, The Field Museum, USA, 72 pp.

Medina-Castro, Y. E.; B. Roldán-Clara y J. C. Leyva -Aguilera (2019). Impactos del turismo en dos Parques Nacionales y áreas aledañas de Baja California, México: el caso de Sierra de San Pedro Mártir y Constitución de 1857. Sociedad y Ambiente, año 7, (19) 165-194.

Millán, M. (2001). Interrelación entre la actividad turística y los espacios naturales protegidos, Cuadernos de Turismo, (7) 93-110.

Morea, J. P. (2016) Metodologías de planificación del uso público en espacios protegidos: antecedentes y perspectivas futuras, Papeles de Geografía, 62, pp. 119-136.

Moretti, E., E. Salinas y A. Ribeiro (2016). El Ecoturismo en Áreas Cársicas Tropicales: Parque Nacional Sierra da Bodoquena, Mato Grosso do Sul, Brasil y Parque Nacional Viñales, Pinar Del Rio, Cuba, Gran Tour: Revista de Investigaciones Turísticas (13) 82-104.

Muñoz-Santos, M.; Benayas, J. (2012). A Proposed Methodology to Assess the Quality of Public Use Management in Protected Areas, Environmental Management (50) $106-122$.

MVOTMA (2014). Directrices para la Planificación del Uso público de las áreas protegidas de Uruguay, Ministerio de Vivienda Ordenamiento Territorial y Medio Ambiente, Montevideo, $46 \mathrm{pp}$.

OEA (1978). Metodología de Inventario Turístico, Organización de los Estados Americanos, Washington: OEA.

OMT (1978). Evaluación de los recursos turísticos, Organización Mundial del Turismo, Madrid.

OMT (2001). Código Ético Mundial para el Turismo. Por un Turismo Responsable. Recuperado de: https://webunwto.s3.eu-west-1.amazonaws.com/s3fs-public/2019-10/gcetpassportglobalcodees.pdf

OMT (2015). Carta Mundial del Turismo Sostenible. Recuperado de: http:// cartamundialdeturismosostenible2015.com/wp-content/uploads/2016/05/CartaMundial-de-Turismo-Sostenible-20.pdf

Prats, Ll. (2003). Patrimonio + turismo= ¿Desarrollo?, Pasos, Revista de turismo y patrimonio cultural, vol. 1, (2) 127-136.

Quesada de Castro R. (2010). Elementos de Turismo. Teoría, clasificación y actividades, Segunda Edición, Editorial Universidad Estatal a Distancia EUNED), San José Costa Rica, 480 pp. 
Ramón, A., Salinas, E. y Lorenzo, C. (2013). Propuesta metodológica para la zonificación funcional de áreas naturales protegidas terrestres desde la perspectiva del paisaje, Revista Instituto Forestal, Sao Paulo. Volumen 25 (1) 7-23.

Reguero, M. del (2004). 10 Estrategias que fomentan la sostenibilidad del ecoturismo, Centro Nacional de Educación Ambiental, Madrid, España, 10 pp.

Rodrigues, C. G. O. (2009). O uso público nos parques nacionais: a relação entre a esfera pública e privada na apropriação da biodiversidade, Tesis de Doctorado, Centro de Desenvolvimento Sustentável, Universidade de Brasília, Brasília, 358 pp.

Rodrigues, S. y E. Pinheiro do Nascimento (2012). Uso público em unidades de conservação: fragilidades e oportunidades para o turismo na utilização dos serviços ecossistêmicos, Somanlu, ano 12, (1) 173-190.

Salinas, E y Câmara, F. (2016). El Turismo de Observación de Aves en Cuba. Investigaciones Turísticas, (12) 20-49.

Salinas, E. y Ramón, A. (2016). Gestión de paisaje y áreas protegida, en: Los Paisajes como Fundamento de la Planificación y Gestión de las Áreas Protegidas Terrestres, Editorial Ambiental, Fondo Verde, Perú, 59 pp.

UNEP y UNWTO (2012). Tourism in the Green Economy- Background Report. Madrid, United Nations World Tourism Organization, Madrid, España.

Vacas, T. (2010). Patrimonio natural: uso público-turístico en los espacios naturales protegidos españoles, Estudios Turísticos, (186) 69-91.

Verdecia, J., M., Carrazana, O. Labrada, Y. Salazar, y Ramón, A. (2016). Plan de Manejo 20172021 Parque Nacional Pico Bayamesa (Inédito) Empresa Nacional para la Protección de la Flora y la Fauna, Ministerio de la Agricultura, Granma, Cuba, 273 pp.

Vilas, R. (2004). Modelo Conceituai para Planejamento e Gestão de Programas Turísticos e Recreativos em Áreas Naturais, Turismo em Análise, v. 15, (1) 89-102.

Zalles, J. I. (2018). Turismo basado en naturaleza y conservación biológica: decisiones de uso de suelo en Mindo, Letras Verdes. Revista Latinoamericana de Estudios Socioambientales (23) $178-198$. 